\title{
Separation of Copper from Electric Cable Waste Based on Mineral Processing Methods: A Case Study
}

\author{
Fernando Pita *(D) and Ana Castilho \\ Geosciences Centre, Department of Earth Sciences, Faculty of Sciences and Technology, University of Coimbra, \\ 3030-790 Coimbra, Portugal; amcastil@dct.uc.pt \\ * Correspondence: fpita@ci.uc.pt
}

Received: 19 September 2018; Accepted: 6 November 2018; Published: 8 November 2018

\begin{abstract}
Recycling of electrical cable waste requires a separation between the metal and the insulating material. The objective of this work was to separate the copper from the plastic in electrical cable waste previously ground below $2 \mathrm{~mm}$, using jigging, shaking table and froth flotation techniques. The effect of particle size was also analysed. Jigging and shaking table proved to be effective in the separation of copper from plastics. The result was a copper concentrate with a copper grade of about $97 \%$ by both methods and a copper recovery of about $97 \%$. Jigging separation had similar separation efficiencies in the seven-sized fractions, but in shaking table, the separation efficiency improved with an increase in particles size. The separation achieved by froth flotation had lower efficiencies $(85 \%)$, because plastics are naturally hydrophobic and copper presents some hydrophobic behaviour. In this technique, the addition of depressant agents was mandatory for the depression of copper, even at low concentrations. The best results were obtained with concentrations of $10^{-1} \mathrm{mg} / \mathrm{L}$ of sodium sulfide (407410 Sigma-Aldrich, Sigma-Aldrich Corporation, St. Louis, MO, USA) and meso-2,3-Dimercaptosuccinic acid (D7881 Sigma-Aldrich).
\end{abstract}

Keywords: cable waste; copper; jigging; shaking table; froth flotation; particle size

\section{Introduction}

Proper waste management is one of the major environmental concerns of public institutions. Waste management systems cover all actions that seek to recover and recycle materials, looking at waste as a resource, in order to prevent health and environmental problems and to conserve natural resources, reducing the cost of production of many products, such as metals, plastics, glass and paper.

It is not difficult to recycle clean and homogeneous waste, but problems occur when waste is constituted by different materials. One of those composite products is the waste of electrical cables. Electrical cables are composed of a conductor, mostly a copper wire, with a plastic insulation cover. Copper is the most valuable component of the cable that can be recycled. However, the recycling of the cable insulator materials, with lower value, can also be performed.

Copper comes from two sources: extraction and processing (refining) of raw materials, called primary production; and recycling of end-of-life products, called secondary production. In the last decades, the world mining production of copper has grown by 3.2\% per annum to 20 million tonnes in 2017 and its largest producer was Chile (5.6 million tonnes). The total global demand for copper in 2016 was approximately 25 million tonnes and China was its largest consumer with nearly 12 million tonnes [1].

Copper is one of the most recycled metals. It is estimated that in 2016, about $29 \%$ of the copper used came from recycled copper and around $40 \%$ of the demand for copper within Europe was supplied from recycled copper [1].

In recent years, several separation technologies developed in mineral processing engineering, based on the differences in physical and chemical properties, have been applied to separate metals 
and non-metals from electric and electronic waste. Several studies have reviewed the progress and the potential of the available techniques, for the recovery of metals and non-metals from electric and electronic waste [2-8]. These technologies include the application of physical separation, such as gravity methods [9-12]; magnetic separation [13-15]; electrostatic separation by the corona method [13,16,17]; electrical conductivity (Eddy currents) methods [18-20] and froth flotation [11,21-23].

Some of these studies intended to improve the separation of electrical and electronic waste through the use of physical/mechanical means. Two of these processes are gravity separation (especially jigging and shaking table) where the separation is based upon the density difference of materials, and froth flotation where the separation is based upon the hydrophobicity difference of materials.

In jigging, a mixture of solid-water is placed at the bottom of a perforated vessel (jig), through which vertical currents of water are forced, expanding (ascending currents) or compacting (descending currents) the pulsating bed. This promotes particle stratification based on density differences between the constituents of the mixture. The densest particles are kept in the base of the stratum, inside the jigging cell, while the particles with low density move to the superficial layers, being overflowed.

In shaking table, particle separation occurs by the action of backwards and forwards motion (stroke) of the table and by the action of wash water applied along the length of the table. Vertical stratification takes place behind the riffles, with the finest and denser particles being at the bottom, whereas the coarsest and least dense particles remain at the top. Heavy particles are concentrated behind the riffles and move at the upper part of the table, while light particles move downwards the incline of the table with the majority of the water to be discharged at the bottom as tailings.

Froth flotation is the separation method most used in the mining industry. It takes advantage of the selective adhesion of hydrophobic particles to the air and of the hydrophilic particles to the water in a solid/water pulp. The separation takes place in a container (cell or column), filled with water and solid particles, and where air is continuously injected to produce air bubbles. Small quantities of chemical reagents are added to control the hydrophobicity of the particles. Hydrophobic particles adhere, after collision with the air bubbles, and move upwards to the top of the cell where they are collected while hydrophilic particles settle or sink.

This study aims to compare the separation of copper and plastics from electrical cable waste through the use of jigging, shaking table and froth flotation. The effect of particle size on separation efficiency was also investigated.

\section{Materials and Methods}

\subsection{Materials}

Granules of electrical cables waste, from multiple copper wires with plastic insulators that had been previously crushed, were used in this experiment. The degree of liberation is 100\%, i.e., all copper and plastic particles are completely liberated. The single copper wire had a diameter of $0.15 \mathrm{~mm}$. The density of the copper wires, measured by an Ultra Pycnometer (AccuPyc 1330, Micromeritics, Norcross, GA, USA), was $8.84 \mathrm{~g} / \mathrm{cm}^{3}$ and the density of plastic was $1.34 \mathrm{~g} / \mathrm{cm}^{3}$. The particles were sieved into seven-sized fractions: $-0.25 \mathrm{~mm},+0.25-0.35 \mathrm{~mm},+0.35-0.5 \mathrm{~mm},+0.5-0.7,+0.7-1.0 \mathrm{~mm}$, $+1.0-1.4$ and $+1.4-2 \mathrm{~mm}$ (Table 1 ). The mean size of the mixed particles ( $\mathrm{d}_{50}$ from cumulative frequency plot) was $0.59 \mathrm{~mm}$. The mean size of copper particles was $0.33 \mathrm{~mm}$ and the mean size of plastic particles was $1.03 \mathrm{~mm}$. Most of the copper particles have sizes below $0.5 \mathrm{~mm}(88.6 \%$ by weight) against plastic particles that have sizes greater than $0.5 \mathrm{~mm}$ (about $84.5 \%$ by weight). 
Table 1. Size and assay distribution of copper and plastic of granulates electrical cable waste.

\begin{tabular}{cccccc}
\hline \multirow{2}{*}{ Size (mm) } & \multirow{2}{*}{ Weight (\%) } & \multicolumn{2}{c}{ Grade (\%) } & \multicolumn{2}{c}{ Distribution (\%) } \\
\cline { 3 - 6 } & & $\mathbf{C u}$ & Plastic & $\mathbf{C u}$ & Plastic \\
\hline$<0.25$ & 14.0 & 79.6 & 20.4 & 27.2 & 4.8 \\
$0.25-0.35$ & 14.1 & 80.6 & 19.4 & 27.8 & 4.6 \\
$0.35-0.50$ & 17.3 & 79.1 & 20.9 & 33.6 & 6.1 \\
$0.50-0.7$ & 11.5 & 25.1 & 74.9 & 7.1 & 14.5 \\
$0.7-1.0$ & 12.1 & 10.3 & 89.7 & 3.0 & 18.3 \\
$1.0-1.4$ & 13.0 & 3.3 & 96.7 & 1.1 & 21.3 \\
$1.4-2$ & 18.0 & 0.4 & 99.7 & 0.2 & 30.3 \\
Total & 100.0 & 40.8 & 59.2 & 100.00 & 100.0 \\
\hline
\end{tabular}

\subsection{Jigging}

Tests were carried out in a Denver laboratory jig, with a rectangular section of $10 \mathrm{~cm} \times 15 \mathrm{~cm}$ and a bottom of steel wire screen. The frequency of the diaphragm movement was 250 cycles/minute, and in each test, $1.5 \mathrm{~kg}$ of material was used. The total time of a test was about $15 \mathrm{~min}$. For investigating the effect of the water flow rate in the separation of the copper/plastic mixture by jigging, three tests were conducted (with a water flow rate of 2,3 and $4 \mathrm{~L} / \mathrm{min}$ ). Since plastic has a lower density than copper, plastic is overflowed, and copper is kept inside the jigging cell. The product that overflows in the jigging operation will be designated as floated and the one that remains inside will be designated as sink. After the experiments, the sink was removed from the jig.

\subsection{Shaking Table}

Tests were carried out in a laboratory Wilfley table, with a rectangular shape of $1.25 \mathrm{~m}$ length and $0.55 \mathrm{~m}$ width. It is partially riffled alongside the table motion, and riffles are $4 \mathrm{~mm}$ high on the feed side, decreasing toward the concentrate edge, and the gap between riffles is $15 \mathrm{~mm}$. There are two water supply points: feed water (near the feed box) and wash water. Particles build up behind each riffle and stratification occurs with heavier particles sinking to the bottom. The shaking action of the table carries the heavy particles along the back of each riffle to the concentrate discharge, which will be designated as sink. The light particles are carried with the majority of the water over each riffle and move down the table to the tailings zone, which will be designated as floated. Multiple products can be produced in the wet shaking table by adding splitters. In this work, three products were generated ("light", "heavy" and "middling") by adjusting two splitters. However, after a first pass through the table, the middling product returned once again to the table in order to separate the copper from the plastics. It is expected that the light product will be enriched in plastic and the heavy product will be enriched in copper.

The separation on shaking table is controlled by many operating parameters (inclination, wash water flow rate, feed water flow rate, frequency and amplitude of table movement, feed pulp density). In this work, inclination and wash water flow were analysed (Table 2). In each test $2.5 \mathrm{~kg}$ of material were used. The frequency ( 300 cycles/minute), amplitude of table movement $(8 \mathrm{~mm})$, feed water flow rate $(2 \mathrm{~L} / \mathrm{min})$ and position of the splitters were kept constant during all experiments.

Table 2. Range of the parameters selected for the shaking table study.

\begin{tabular}{cccc}
\hline Parameters & Range \\
\hline Inclination $\left({ }^{\circ}\right)$ & 4 & 5.5 & 7 \\
Wash water flow rate $(\mathrm{L} / \mathrm{min})$ & 3 & 4.5 & 6 \\
\hline
\end{tabular}




\subsection{Froth Flotation}

The froth flotation assays took place in a Denver cell with a capacity of $3 \mathrm{dm}^{3}$ at a low rotational speed of $600 \mathrm{rpm}$. Each test used $50 \mathrm{~g}$ of electric cable waste that was conditioned with sodium sulfide (407410 Sigma-Aldrich) and meso-2,3-Dimercaptosuccinic acid (D7881 Sigma-Aldrich), as depressants agents of copper, for about $5 \mathrm{~min}$ and later with methyl isobutyl carbinol (MIBC) (109916 Sigma Aldrich), as frothing reagent, for about $2 \mathrm{~min}$ before the flotation. Then the air valve was opened, and the floated product was collected for about $6 \mathrm{~min}$. Tap water was used in the flotation tests.

After the experiments of jigging, shaking table and froth flotation, the floated and sink products were dried, screened and weighed. The separation was controlled using the recovery and grade of copper and plastic in the sink and in the floated products, after manual sorting and weighing, the copper and plastic with a laboratory scale (precision $\pm 0.01 \mathrm{~g}$ ). All the experiments were replicate three times under similar operating conditions. The effectiveness of the plastic separation was quantified as $\eta=R_{C U}-R_{P L}$ (where $\eta$ is the separation efficiency, $R_{C U}$ is the recovery of copper in the sink and $R_{P L}$ is the recovery of plastic in the sink) [24].

\section{Results and Discussion}

\subsection{Jigging}

The recovery and grade of copper in the sink (concentrate), and the recovery and grade of plastic in the floated (tailings), as well as the separation efficiency were influenced by the water flow rate (Table 3).

Table 3. Experimental matrix and results of jigging separation (average of three replicates).

\begin{tabular}{cccccc}
\hline \multirow{2}{*}{$\begin{array}{c}\text { Water Flow } \\
\text { Rate (L/min) }\end{array}$} & \multicolumn{2}{c}{ Sink } & \multicolumn{2}{c}{ Floated } & Separation \\
\cline { 2 - 5 } & $\begin{array}{c}\text { Copper } \\
\text { Recovery (\%) }\end{array}$ & $\begin{array}{c}\text { Copper } \\
\text { Grade (\%) }\end{array}$ & $\begin{array}{c}\text { Plastic } \\
\text { Recovery (\%) }\end{array}$ & $\begin{array}{c}\text { Plastic } \\
\text { Grade (\%) }\end{array}$ & Efficiency (\%) \\
\hline 2 & 98.4 & 91.6 & 93.8 & 98.8 & 92.2 \\
3 & 97.8 & 96.7 & 97.7 & 98.5 & 95.5 \\
4 & 94.6 & 97.8 & 98.5 & 96.4 & 93.1 \\
\hline
\end{tabular}

The recovery of copper and plastic in the sink decreased with increasing water flow rate. The highest recovery of copper in the sink $(98.4 \%)$ was obtained for the lowest water flow rate ( $2 \mathrm{~L} / \mathrm{min})$. On the contrary, the highest recovery of plastic in the floated $(98.5 \%)$ was obtained for the greatest water flow rate $(4 \mathrm{~L} / \mathrm{min})$. By increasing the water flow rate from 2 to $3 \mathrm{~L} / \mathrm{min}$ the recovery of copper in the sink was almost constant, but the grade of copper increased, because the recovery of plastic in the sink decreased. However, by increasing the water flow rate from 3 to $4 \mathrm{~L} / \mathrm{min}$, the recovery of copper in the sink decreased, and the recovery of plastic in the floated was almost constant.

The highest separation efficiency $(95.5 \%)$ was obtained with an intermediate water flow rate of $3 \mathrm{~L} / \mathrm{min}$, with a copper recovery of $97.8 \%$. Sarvar et al. [23] obtained similar results in wet jigging separation of metals from computer printed circuit boards of the $0.59-1.68 \mathrm{~mm}$ size fraction, with a metal recovery in the sink of $97.5 \%$ and a metal grade of $92.5 \%$. Also, He et al. [12] separated the same material but with an active pulsing air classifier, achieving a maximum separation efficiency of $92.4 \%$ and a metal recovery of $96.2 \%$.

\subsection{Shaking Table}

To evaluate the effect of inclination and wash water flow rate in the separation of copper/plastic mixture by wet shaking table, nine tests sets were performed (Table 4 ). The grade and recovery of copper in the sink (concentrate zone), the grade and recovery of plastic in the floated (tailings 
zone), and the separation efficiency were strongly influenced by the table inclination and wash water flow rate.

Table 4. Experimental matrix and results of shaking table separation (average of three replicates).

\begin{tabular}{|c|c|c|c|c|c|c|}
\hline \multicolumn{2}{|c|}{ Experimental Conditions } & \multicolumn{2}{|c|}{ Sink } & \multicolumn{2}{|c|}{ Floated } & \multirow{2}{*}{$\begin{array}{c}\text { Separation } \\
\text { Efficiency (\%) }\end{array}$} \\
\hline Inclination $\left(^{\circ}\right)$ & $\begin{array}{c}\text { Wash Water Flow } \\
\text { Rate (L/min) }\end{array}$ & $\begin{array}{c}\text { Copper } \\
\text { Recovery (\%) }\end{array}$ & $\begin{array}{c}\text { Copper } \\
\text { Grade }(\%)\end{array}$ & $\begin{array}{c}\text { Plastic } \\
\text { Recovery (\%) }\end{array}$ & $\begin{array}{c}\text { Plastic } \\
\text { Grade (\%) }\end{array}$ & \\
\hline 4 & 3 & 99.7 & 68.8 & 68.8 & 99.7 & 68.6 \\
\hline 4 & 4.5 & 97.7 & 81.0 & 84.2 & 98.1 & 81.9 \\
\hline 4 & 6 & 84.8 & 87.4 & 91.6 & 89.7 & 76.4 \\
\hline 5.5 & 3 & 98.5 & 83.5 & 86.6 & 98.8 & 85.1 \\
\hline 5.5 & 4.5 & 96.6 & 97.4 & 98.2 & 97.7 & 94.8 \\
\hline 5.5 & 6 & 72.8 & 99.1 & 99.6 & 84.2 & 72.4 \\
\hline 7 & 3 & 75.2 & 90.5 & 94.5 & 84.7 & 69.7 \\
\hline 7 & 4.5 & 62.1 & 99.4 & 99.8 & 79.8 & 62.9 \\
\hline 7 & 6 & 35.7 & 100.0 & 100.0 & 69.3 & 35.7 \\
\hline
\end{tabular}

The highest recovery of copper in the sink $(99.7 \%)$ was obtained with the lowest table inclination and the lowest wash water flow rate. The highest recovery of plastic in the floated $(100 \%)$ was obtained with a maximum of table inclination and wash water flow rate. As the table inclination or the wash water flow rate increased, the transport of copper to the floated product increased, which in turn decreased the recovery of copper in the sink product. Moreover, as the table inclination or the wash water flow rate increased, the transport of plastic to the floated product increased which, in turn, improved the grade of copper in the sink product.

The best separation efficiency (near 95\%) was obtained for intermediate levels of table inclination of $5.5^{\circ}$ and wash water flow rate of $4.5 \mathrm{~L} / \mathrm{min}$, with a copper grade of $97 \%$ in the sink and a copper recovery of $96.6 \%$ (Table 4). These results were better than the ones obtained by Koyanaka et al. [9] in the separation of copper/plastic mixture using an inclined vibrating plate, getting a separation efficiency of $73 \%$, a copper grade of $97 \%$ and a copper recovery of about $80 \%$.

The effect of table inclination depends on the value of wash water flow rate and vice versa (Figure 1). When wash water flow rate was at the highest level $(6 \mathrm{~L} / \mathrm{min})$, a change in table inclination level had a greater effect on copper recovery than the one observed when wash water flow was at its lowest level (3 L/min) (Figure 1a). For plastic recovery, the opposite was observed, with a higher effect of table inclination when wash water flow rate was at a lower level (Figure 1b).

When table inclination was at the highest level $\left(7^{\circ}\right)$, a change in wash water flow rate had a greater effect in copper recovery than the one observed when table inclination was set at its lowest level $\left(4^{\circ}\right)$ (Figure 1c). For plastic recovery, the opposite was observed, with a higher effect of wash water flow rate when table inclination was set at a lower level (Figure 1d).

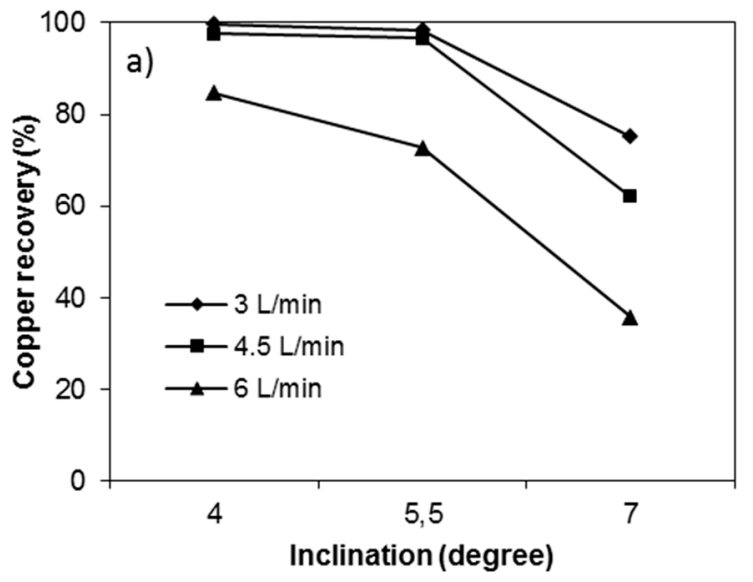

Figure 1. Cont. 

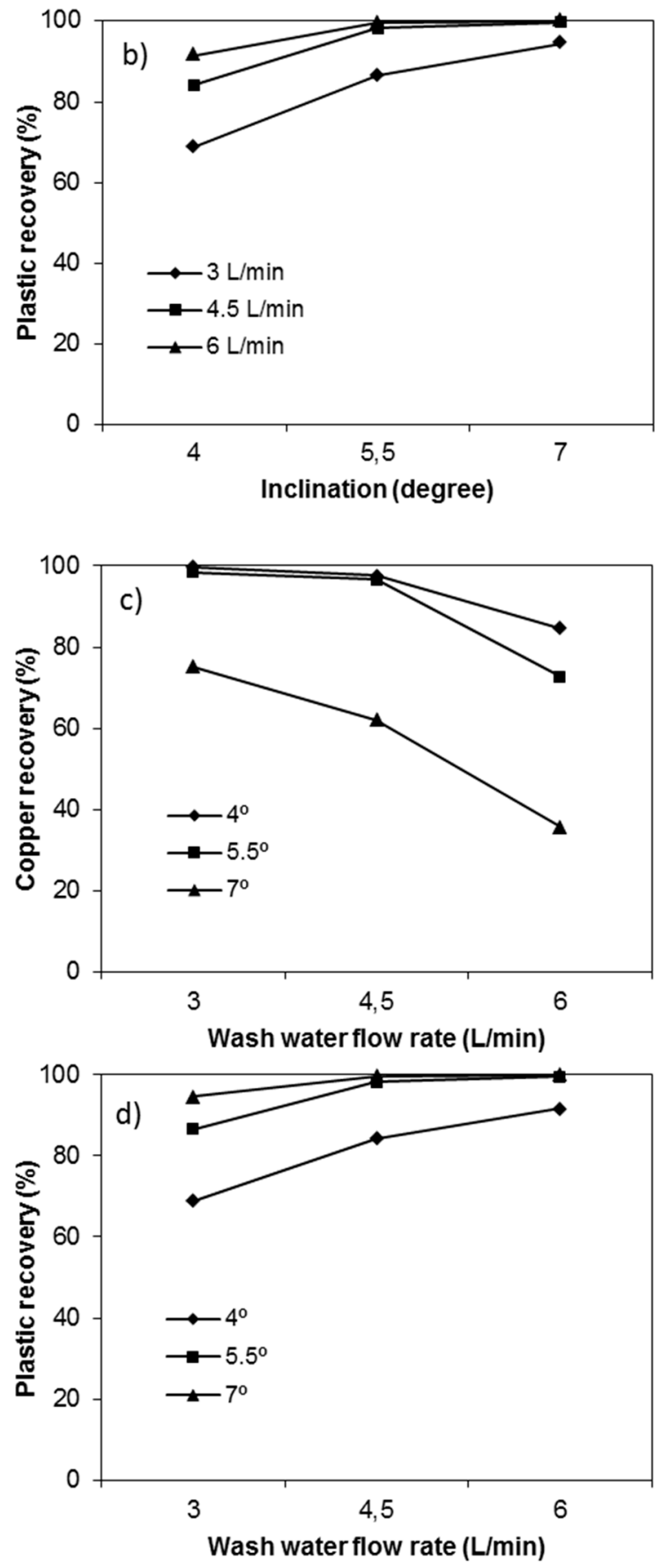

Figure 1. Effect of interaction between table inclination and wash water flow rate on copper recovery $(\mathbf{a}, \mathbf{c})$ and on plastic recovery $(\mathbf{b}, \mathbf{d})$.

\subsection{Froth Flotation}

Firstly, flotation separation tests were carried out with only a frother reagent (MIBC). Figure 2 shows the recovery and grade of copper in the sink (concentrate) and plastics recovery and grade in the floated (tailing) versus MIBC concentration. Although the flotation recovery of plastic was clearly greater than the copper recovery, the flotation recovery of copper was significant, and so the selectivity of flotation separation was not good. Plastics are naturally hydrophobic, and their flotation recovery is high. Plastic and copper showed a similar variation of the floatability with MIBC concentration. So, the effect of the froth type, for different MIBC concentrations, influenced in the flotation a similar way to the plastic and copper. Plastic and copper had higher floatabilities with intermediate MIBC 
concentrations $(90 \mathrm{mg} / \mathrm{L})$. The lowest recovery of plastic and copper was obtained for the lowest and highest concentration of MIBC (15 and $180 \mathrm{mg} / \mathrm{L})$. This was a consequence of the formation of weak froth, for low concentrations of MIBC ( $15 \mathrm{mg} / \mathrm{L})$, and a consequence of the formation of a very thick and stable froth that had limited the rise of the particles for high concentrations of MIBC $(180 \mathrm{mg} / \mathrm{L})$.

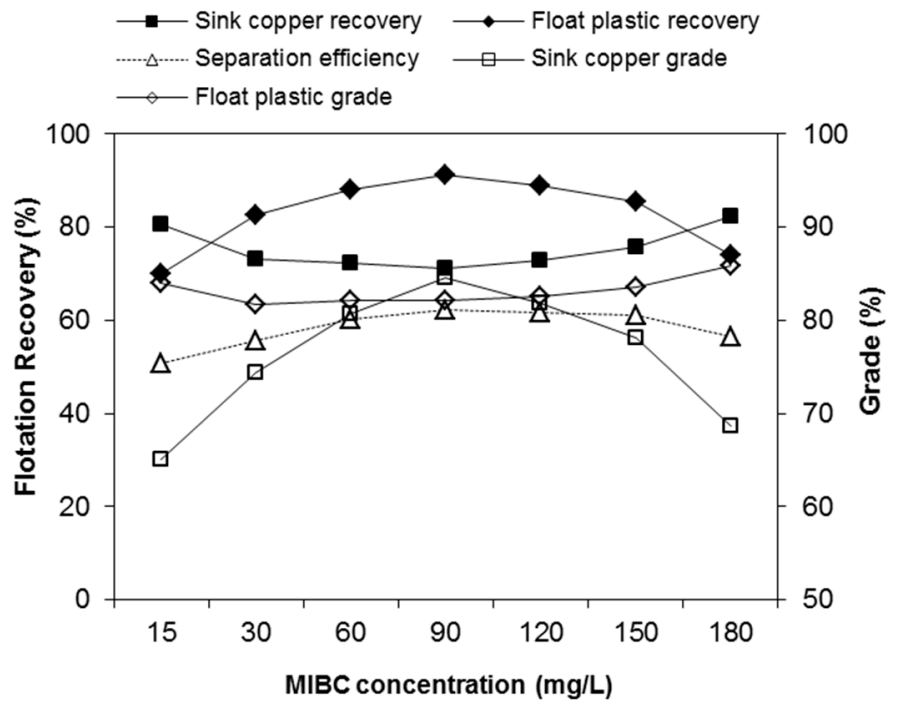

Figure 2. Recovery and grade of copper in the sink and of plastic in the floated, and separation efficiency versus MIBC concentration.

The best results were obtained with an intermediate concentration of MIBC $(90 \mathrm{mg} / \mathrm{L})$ with a copper grade of $84.6 \%$ in the sink (Figure 2). Copper recovery in the sink was $71.2 \%$ and plastic recovery in the floated was $91.1 \%$. These results were better than those obtained by Ogunniyi and Vermaak [21] in a study for beneficiation of printed circuit boards by froth flotation, where the maximum copper recovery in the sink was $66 \%$. Also, Sarvar et al. [23] in froth flotation separation of metals from computer printed circuit boards of size fractions lower than $0.59 \mathrm{~mm}$, obtained worse results, with a metal recovery in the sink of $85.7 \%$, a metal grade of $75 \%$, and a separation efficiency of $45.25 \%$. However, these results were not as good as those obtained by Gallegos-Acevedo et al. [22], in a study for beneficiation of printed circuit boards by froth flotation, where the maximum separation efficiency was $85.32 \%$, the metal recovery in the sink was $92.62 \%$ and the fiberglass recovery in the floated was $92.70 \%$.

Since copper presented some hydrophobic behaviour, because part of it was floated, it was necessary to test some copper depressants in order to promote its wettability and consequent depression. After the use of some potential copper depressants such as N-(1-Naphthyl)ethylenediamine dihydrochloride (N9125 Sigma-Aldrich), starch (S4251 Sigma-Aldrich), sodium metabisulfite (255556 Sigma-Aldrich), sodium sulfide (407410 Sigma-Aldrich) and meso-2,3-Dimercaptosuccinic acid (D7881 Sigma-Aldrich), it was found that these last two reagents led to the best results, having depressed almost all copper.

Figure 3 shows the recovery and grade of copper in the sink, recovery and grade of plastic in the floated and separation efficiency versus concentration of these two copper depressor agents (sodium sulfide and meso-2,3-Dimercaptosuccinic acid), with an MIBC concentration of $90 \mathrm{mg} / \mathrm{L}$. The two depressor agents showed similar effects on the floatability of copper. Flotation recovery of copper decreased with the increase of the two depressants concentration. These depressor agents had low effects on plastic flotation, with only a significant decrease in plastic flotation observed at a high concentration of sodium sulfide. Recovery of copper in the sink is about $98 \%$ for a concentration of $10 \mathrm{mg} / \mathrm{L}$ of the two depressor agents.

The best separations were obtained with $10^{-1} \mathrm{mg} / \mathrm{L}$ concentration of the two depressor agents, with the highest separation efficiencies (near $85 \%$ ). For this depressor concentration and for the two 
depressor agents, we obtained a sink with a grade of $87 \%$ in copper and a copper recovery of about 95\% (Figure 3).
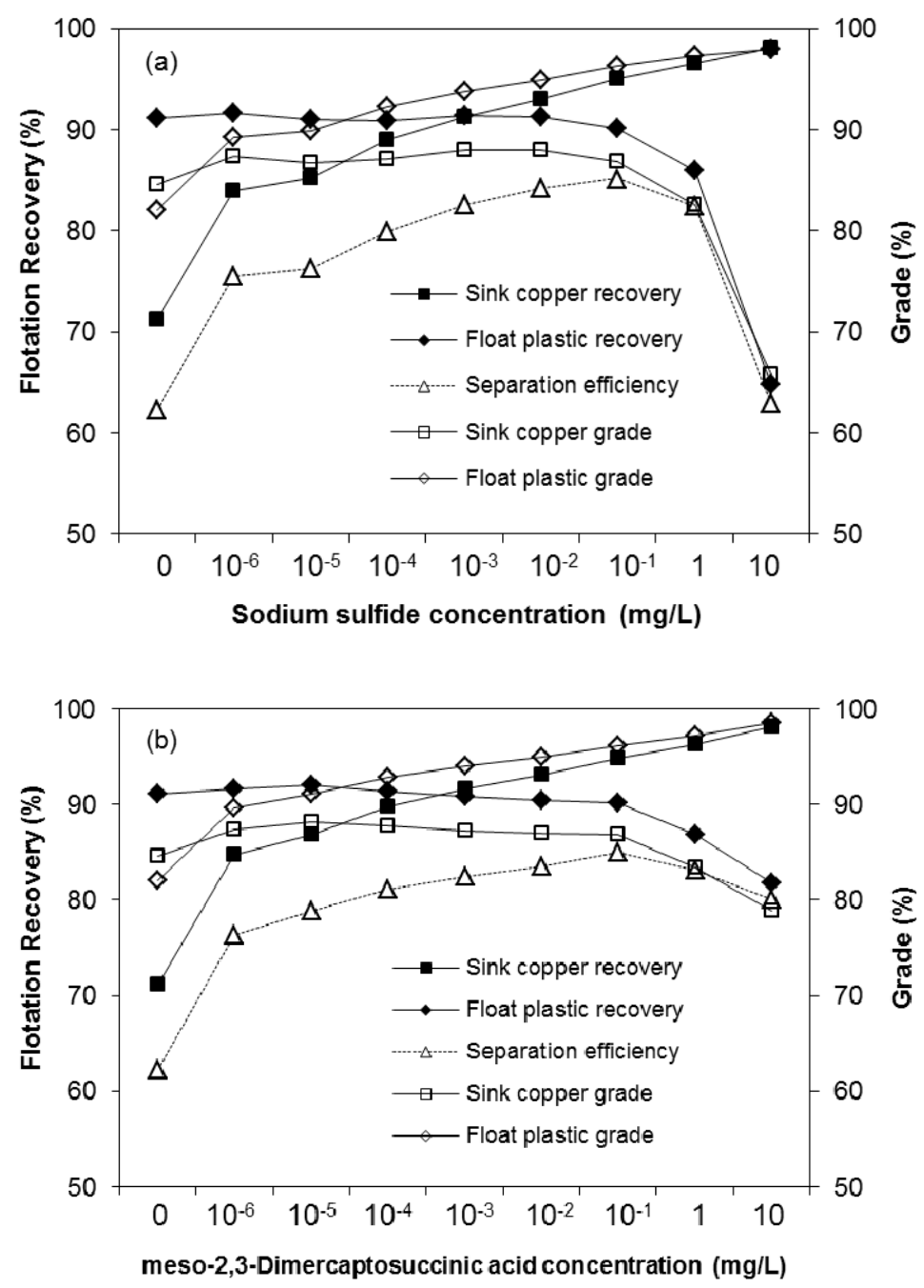

Figure 3. Recovery and grade of plastic in the floated, recovery and grade of copper in the sink, and separation efficiency versus sodium sulfide (a) and meso-2,3-Dimercaptosuccinic acid (b) concentration.

Considering the flotation test that led to the best results, that is, in the presence of sodium sulfide at a concentration of $10^{-1} \mathrm{mg} / \mathrm{L}$, and comparing the three separation methods, it was verified that froth flotation presented smaller separation efficiencies than jigging and shaking table. Jigging and shaking table separations led to similar results, with a separation efficiency of about $95 \%$. Recovery of copper in the froth flotation was slightly smaller than the recovery of copper in the jigging and shaking table. Also, the recovery of plastic in the froth flotation was smaller than the recovery of plastic in the jigging and shaking table. The copper grade of the sink in jigging and shaking table was about $97 \%$ with a copper recovery of about $97 \%$, and the copper grade of the sink in froth flotation was $86.9 \%$ with a copper recovery of $95.1 \%$.

\subsection{Effect of Particle Size in the Three Methods of Separation}

The size of the particles is an important factor in the separation by froth flotation and by gravity. Hence, the influence of the particle size in the separation of a copper/plastic mixture by the three 
methods was analysed. The results of jigging, shaking table and froth flotation tests that led to better separations, for seven-sized fractions, are presented in Table 5.

Table 5. Results of separation by jigging, shaking table and flotation of the copper/plastic mixture, for seven-sized fractions.

\begin{tabular}{|c|c|c|c|c|c|c|}
\hline & \multirow{2}{*}{$\begin{array}{l}\text { Size Fraction } \\
(\mathrm{mm})\end{array}$} & \multicolumn{2}{|c|}{ Sink } & \multicolumn{2}{|c|}{ Floated } & \multirow{2}{*}{$\begin{array}{l}\text { Separation } \\
\text { Efficiency } \\
\text { (SE) }(\%)\end{array}$} \\
\hline & & $\begin{array}{c}\text { Copper } \\
\text { Recovery (\%) }\end{array}$ & $\begin{array}{l}\text { Copper } \\
\text { Grade }(\%)\end{array}$ & $\begin{array}{c}\text { Plastic } \\
\text { Recovery (\%) }\end{array}$ & $\begin{array}{c}\text { Plastic } \\
\text { Grade (\%) }\end{array}$ & \\
\hline \multirow{7}{*}{ 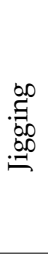 } & $<0.25$ & 96.2 & 99.8 & 99.4 & 87.1 & 95.6 \\
\hline & $+0.25-0.35$ & 98.1 & 99.7 & 98.9 & 92.5 & 97.0 \\
\hline & $+0.35-0.5$ & 98.7 & 99.6 & 98.6 & 95.2 & 97.3 \\
\hline & $+0.5-0.7$ & 98.5 & 93.9 & 97.9 & 99.5 & 96.4 \\
\hline & $+0.7-1.0$ & 98.4 & 82.7 & 97.7 & 99.8 & 96.1 \\
\hline & $+1.0-1.4$ & 98.3 & 58.0 & 97.6 & 99.9 & 95.9 \\
\hline & $+1.4-2.0$ & 98.6 & 10.4 & 97.0 & 100.0 & 95.6 \\
\hline \multirow{7}{*}{ 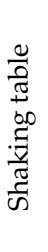 } & $<0.25$ & 93.9 & 98.3 & 93.5 & 79.9 & 87.4 \\
\hline & $+0.25-0.35$ & 97.3 & 98.6 & 94.4 & 89.2 & 91.7 \\
\hline & $+0.35-0.5$ & 97.8 & 98.7 & 95.1 & 92.1 & 92.9 \\
\hline & $+0.5-0.7$ & 97.7 & 90.5 & 96.6 & 99.2 & 94.3 \\
\hline & $+0.7-1.0$ & 97.8 & 90.6 & 98.8 & 99.8 & 96.6 \\
\hline & $+1.0-1.4$ & 98.1 & 85.1 & 99.4 & 99.9 & 97.5 \\
\hline & $+1.4-2.0$ & 98.7 & 50.4 & 99.7 & 100.0 & 98.4 \\
\hline \multirow{7}{*}{ 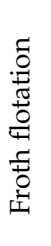 } & $<0.25$ & 90.4 & 100.0 & 100.0 & 72.8 & 90.4 \\
\hline & $+0.25-0.35$ & 95.6 & 99.6 & 98.4 & 84.4 & 94.0 \\
\hline & $+0.35-0.5$ & 97.0 & 99.3 & 97.3 & 89.6 & 94.3 \\
\hline & $+0.5-0.7$ & 98.0 & 89.7 & 96.2 & 99.3 & 93.2 \\
\hline & $+0.7-1.0$ & 99.3 & 69.2 & 94.9 & 99.9 & 94.2 \\
\hline & $+1.0-1.4$ & 100.0 & 29.9 & 92.1 & 100.0 & 92.1 \\
\hline & $+1.4-2.0$ & 100.0 & 1.62 & 78.6 & 100.0 & 78.6 \\
\hline
\end{tabular}

In jigging, the recovery of copper in the sink was the lowest for the finer fraction and the recovery of plastic in the floated slightly increased with increasing particles size (Table 5). While in the jigging separation of ores, the finer particles of the heaviest mineral were in the lower strata of the jigging bed, in the case of copper the opposite was observed. During the bed expansion, the finest particles of copper and plastic were more easily elevated in the jigging bed than the coarser ones, making them more prone to overflow. Jigging separation of the copper/plastic mixture had similar separation efficiencies in the seven-sized fractions (Table 5). For all size fractions, the separation efficiency values changed less than $2 \%$, with separation efficiencies of about $96 \%$. For the three finer fractions, the sink was a product of almost pure copper, and for the four coarser fractions, the floated was a product of almost pure plastic.

In shaking table, plastic recovery in the floated increased with increasing particles size (Table 5). In the shaking table separation of ores, the finer particles were in the lower strata of the table bed. During the stratification operated in the shaking table, the coarser particles of plastic occupied the upper strata and were, therefore, more easily carried by the wash water into the floated. However, recovery of copper in the sink was lowest for the finer fraction, i.e., the recovery of copper in the floated was highest for the finer fraction. The separation efficiency slightly improved with an increase in particles size. For the four coarser fractions, the floated was a product of almost pure plastic.

In the flotation tests, the copper and plastic recovery in the sink increased with increasing particles size. Other authors also verified that small plastic particles are easier to float than coarse ones [25-28]. Moreover, Sarvar et al. [23] verified that metal recovery in the floated decreased with increasing particles size.

Separation by froth flotation was not as effective as the other two methods for the coarser particles because of the greater weight and size of the particles and the depression of plastic. Also, the plastic-bubble aggregates may not be as stable in the coarser fractions as in the finer ones [29]. That could arise, to a certain extent, from the disintegration of the bubble-plastic particle aggregates 
formed under the conditions of the flotation method used (flotation cell). Bubbles attached on the surface of plastics are subjected to shear forces and pressure changes under turbulent conditions, which can cause the disintegration of the plastic-bubble aggregates. In this case, such particles are not able to escape from the main flow in the flotation cell [29]. In fact, studies show that floated recovery of plastics decreased with increased mixing speed in the flotation cell [29-32]. It has also been found that large particles are more affected than small ones. Fraunholcz [29] affirmed that pneumatically aerated low-turbulence flotation devices (like flotation columns), are more suitable for the flotation of plastics than flotation machines, because they provide the quiescent conditions required for bubble particle adhesion.

Lower sink copper recovery in the finer fractions was due to fine-sized particles, which are more easily entrained in the froth flotation. The intermediate size fractions presented separation efficiencies of around $94 \%$. For the three finer fractions, the sink presented a product almost pure in copper, because the recovery of plastic in the floated was high. For the coarser fraction, the sink presented a low copper grade, because the recovery of plastic in the sink was significant $(21.4 \%)$ and the copper content in that size fraction of the feed was low $(0.4 \%)$.

\section{Conclusions}

Separation of copper from plastic in electric cable waste was successfully achieved by jigging and shaking table, presenting a separation efficiency of about $95 \%$. In both methods, it was possible to obtain a sink product with a copper grade of $97 \%$ and a copper recovery of $97 \%$, and a floated product with a plastic grade of about $98 \%$ and a plastic recovery of $98 \%$. In jigging separation, the influence of particle size was minimal, but in shaking table, the separation efficiency was slightly improved by the increase in particles size, and the maximum separation efficiency occurred in the coarser fraction.

Results showed that plastic was naturally floatable, and copper presented some natural floatability. The best flotation separations were obtained in the presence of sodium sulfide and meso-2,3-Dimercaptosuccinic acid, which decreased copper floatability. In the tested conditions, froth flotation was not as effective as jigging and shaking table, nevertheless, it led to a separation efficiency of $85 \%$. Separation by froth flotation presented the worst results for the coarser particles, with a separation efficiency of $79 \%$. This was a consequence of the lower floatability of the coarser plastic particles, because they are more difficult to float and also less stable with turbulent flowing conditions. For the others size fractions, the flotation presented separation efficiencies similar to the shaking table and jigging.

The results obtained showed that jigging, shaking table and flotation are potential methods for separating copper/plastics mixtures. Furthermore, the control of particle size is important in the separation of this mixture by shaking table and froth flotation. In the three separation methods, for the three fine fractions, the sink was a product of almost pure copper, and for the four coarse fractions, the floated was a product of almost pure plastic.

In the future, the authors intend to use a flotation column to test the separation of copper and plastic mixtures with coarse particles.

Author Contributions: F.P. conceived and designed the experiments; F.P. and A.C. analysed the data; F.P. wrote the original draft; F.P. and A.C. revised and edited the manuscript.

Funding: This work was supported by the Portuguese Foundation for Science and Technology (FCT-MEC) through national funds and, when applicable, co-financed by FEDER in the ambit of the partnership PT2020, through the following research projects: UID/Multi/00073/2013 of the Geosciences Center of the University of Coimbra.

Conflicts of Interest: The authors declare no conflict of interest. 


\section{References}

1. (ICSG) International Copper Study Group. The World Copper Factbook 2018. 2018. Available online: https:/ / www.icsg.org/index.php/component/jdownloads/finish/170/2876 (accessed on 22 June 2018).

2. Guo, J.; Guo, J.; Xu, Z. Recycling of non-metallic fractions from waste printed circuit boards: A review. J. Hazard. Mater. 2009, 168, 567-590. [CrossRef] [PubMed]

3. Canal Marques, A.; Cabrera, J.M.; Malfatti, C.F. Printed circuit boards: A review on the perspective of sustainability. J. Environ. Manag. 2013, 131, 298-306. [CrossRef] [PubMed]

4. Wang, R.; Xu, Z. Recycling of non-metallic fractions from waste electrical and electronic equipment (WEEE)-A review. Waste Manag. 2014, 34, 1455-1469. [CrossRef] [PubMed]

5. Ghosh, B.; Ghosh, M.K.; Parhi, P.; Mukherjee, P.S.; Mishra, B.K. Waste printed circuit boards recycling: An extensive assessment of current status. J. Clean. Prod. 2015, 94, 5-19. [CrossRef]

6. Kaya, M. Recovery of metals from electronic waste by physical and chemical processes. Waste Manag. 2016, 57, 64-90. [CrossRef] [PubMed]

7. Zhang, L.; $\mathrm{Xu}, \mathrm{Z}$. A review of current progress of recycling technologies for metals from waste electrical and electronic equipment. J. Clean. Prod. 2016, 127, 19-36. [CrossRef]

8. Chauhan, G.; Jadhao, P.R.; Pant, K.J.; Nigam, K.D.P. Novel technologies and conventional processes for recovery of metals from waste electrical and electronic equipment: Challenges \& opportunities-A review. J. Environ. Chem. Eng. 2018, 6, 1288-1304.

9. Koyanaka, S.; Ohya, H.; Endoh, S.; Iwata, H.; Ditl, P. Recovering copper from electric cable wastes using a particle shape separation technique. Adv. Powder. Technol. 1997, 8, 103-111. [CrossRef]

10. Cui, J.; Forssberg, E. Mechanical recycling of waste electric and electronic equipment: A review. J. Hazard. Mater. 2003, 99, 243-263. [CrossRef]

11. Das, A.; Vidyadhar, A.; Mehrotra, S.P. A novel flowsheet for the recovery of metal values from waste printed circuit boards. Resour. Conserv. Recycl. 2009, 53, 464-469. [CrossRef]

12. He, J.F.; Duan, C.L.; He, Y.Q.; Zhang, H.J. Recovery of valuable metal concentrate from waste printed circuit boards by a physical beneficiation technology. Int. J. Environ. Sci. Technol. 2015, 12, 2603-2612. [CrossRef]

13. Veit, H.M.; Diehl, T.R.; Salami, A.P.; Rodrigues, J.S.; Bernardes, A.M.; Tenório, J.A.S. Utilization of magnetic and electrostatic separation in the recycling of printed circuit boards scrap. Waste Manag. 2005, 25, 67-74. [CrossRef] [PubMed]

14. Chao, G.; Hui, W.; Wei, L.; Jiangang, F.; Xin, Y. Liberation characteristic and physical separation of printed circuit board (PCB). Waste Manag. 2011, 31, 2161-2166.

15. Yamane, L.H.; Moraes, V.T.; Espinosa, D.C.R.; Tenório, J.A. Recycling of WEEE: Characterization of spent printed circuit boards from mobile phones and computers. Waste Manag. 2011, 31, 2553-2558. [CrossRef] [PubMed]

16. Wu, J.; Li, J.; Xu, Z.-M. A new two-roll electrostatic separator for recycling of metals and nonmetals from waste printed circuit board. J. Hazard. Mater. 2009, 161, 257-262.

17. Hadi, P.; Xu, M.; Lin, C.S.K.; Hui, C.W.; McKay, G. Waste printed circuit board recycling techniques and product utilization. J. Hazard. Mater. 2015, 283, 234-243. [CrossRef] [PubMed]

18. Zhang, S.L.; Forssberg, E. Mechanical recycling of electronics scrap-The current status and prospects. Waste Manage. Res. 1998, 16, 119-128. [CrossRef]

19. Kasper, A.C.; Berselli, G.B.T.; Freitas, B.D.; Tenório, J.A.S.; Bernardes, A.M.; Veit, H.M. Printed wiring boards for mobile phones: Characterization and recycling of copper. Waste Manag. 2011, 31, 2536-2545. [CrossRef] [PubMed]

20. Ruan, J.; $\mathrm{Xu}, \mathrm{Z}$. Constructing environment-friendly return road of metals frome-waste: Combination of physical separation technologies. Renew. Sustain. Energ. Rev. 2016, 54, 745-760. [CrossRef]

21. Ogunniyi, I.O.; Vermaak, M.K.G. Investigation of froth flotation for beneficiation of printed circuit board comminution fines. Miner. Eng. 2009, 22, 378-385. [CrossRef]

22. Gallegos-Acevedo, P.M.; Espinoza-Cuadra, J.; Olivera-Ponce, J.M. Conventional Flotation Techniques to Separate Metallic and Nonmetallic Fractions from Waste Printed Circuit Boards with Particles Nonconventional Size. J. Min. Sci. 2014, 50, 974-981. [CrossRef] 
23. Sarvar, M.; Salarirad, M.M.; Shabani, M.A. Characterization and mechanical separation of metals from computer Printed Circuit Boards (PCBs) based on mineral processing methods. Waste Manag. 2015, 45, 246-257. [CrossRef] [PubMed]

24. Schulz, N.F. Separation efficiency. Trans. SME/AIME 1970, 247, 81-87.

25. Marques, G.A.; Tenório, J.A.S. Use of froth flotation to separate PVC/PET mixtures. Waste Manag. 2000, $20,265-269$. [CrossRef]

26. Shen, H.; Forssberg, E.; Pugh, R.J. Selective flotation separation of plastics by particle control. Resour. Conserv. Recycl. 2001, 33, 37-50. [CrossRef]

27. Wang, C.Q.; Wang, H.; Liu, Y.N. Separation of polyethylene terephthalate from municipal waste plastics by froth flotation for recycling industry. Waste Manag. 2015, 35, 42-47. [CrossRef] [PubMed]

28. Pita, F.; Castilho, A. Separation of plastics by froth flotation. The role of size, shape and density of the particles. Waste Manag. 2017, 60, 91-99. [CrossRef] [PubMed]

29. Fraunholcz, N. Plastics Flotation. Ph.D. Thesis, Delft University of Technology, Delft, The Netherlands, 1997.

30. Buchan, R.; Yarar, B. Recovering plastics for recycling by mineral processing techniques. J. Miner. Met. Mater. Soc. 1995, 47, 52-55. [CrossRef]

31. Okuda, T.; Kurose, K.; Nishijima, W.; Oka, M. Separation of Polyvinyl Chloride from Plastic Mixture by Froth Flotation after Surface Modification with Ozone. Ozone Sci. Eng. 2007, 29, 373-377. [CrossRef]

32. Truc, N.T.T.; Lee, C.-H.; Lee, B.-K.; Mallampati, S.R. Separation of hazardous brominated plastics from waste plastics by froth flotation after surface modification with mild heat-treatment. Int. J. Chem. Mol. Eng. 2015, 9, 1388-1391.

(C) 2018 by the authors. Licensee MDPI, Basel, Switzerland. This article is an open access article distributed under the terms and conditions of the Creative Commons Attribution (CC BY) license (http:/ / creativecommons.org/licenses/by/4.0/). 